When Knowledge Goes Viral: Assessing the Possibility of Virus-Related Traditional Knowledge for Access and Benefit-Sharing

Michelle F Rourke*\#

*Griffith Law School

Griffith University

Gold Coast, Queensland 4222

Australia

\# Australian Defence Force Malaria and Infectious Disease Institute

Gallipoli Barracks

Enoggera, Queensland 4051

Australia

The opinions expressed here are those of the author and do not reflect any views or positions of the Australian Defence Force.

Email: michelle.rourke@griffithuni.edu.au 


\title{
When Knowledge Goes Viral: Assessing the Possibility of Virus-Related Traditional Knowledge for Access and Benefit-Sharing
}

\begin{abstract}
Viruses, like all genetic resources, are subject to Access and Benefit-Sharing (ABS) obligations under the Convention on Biological Diversity (CBD) and its Nagoya Protocol. This requires that access to genetic resources accords with mutually agreed terms and with the prior informed consent of providing parties. Similar conditions must be met for the use of any Traditional Knowledge (TK) associated with genetic resources held by Indigenous Peoples and local communities. While there are many documented cases of TK indirectly associated with viruses, this article will demonstrate that there are indeed instances where TK could be directly associated with viruses. As the utility of viruses in various biotechnological applications becomes ever more apparent, it is time to consider whether the TK provisions of the CBD and Nagoya Protocol might factor into future virus ABS agreements, and whether TK considerations might also affect the suite of intellectual property protections currently afforded to viruses and viral derivatives in some jurisdictions.
\end{abstract}




\section{Introduction}

The Access and Benefit-Sharing (ABS) regimes created by the United Nations' Convention on Biological Diversity (CBD) and its Nagoya Protocol on Access to Genetic Resources and the Fair and Equitable Sharing of the Benefits Arising from their Utilization (Nagoya Protocol), govern the international sharing of genetic resources. While the CBD was broadly conceived as an environmental conservation treaty, it is now more significant as a generalized ABS regime for genetic resources, the implications of which reach well beyond global conservation and sustainability efforts. The CBD reaffirmed the sovereignty of Nation States over their genetic resources, and in doing so, reaffirmed their right to determine the terms governing the access to those resources. By giving States the right to determine the terms of access, the CBD envisaged a sort of quid pro quo that would ensure that the benefits arising from the utilization of sovereign genetic resources would be channelled into environmental protection and sustainability projects (Lawson, 2006, p. 138; Oberthür \& Rosendal, 2014, p. 1). It should be noted that while the United States of America has not ratified the CBD, it is not "legally immune" from recognizing the sovereign rights of States over their genetic resources (Reichman, Uhlir and Dedeurwaerdere, 2016, pp. 161-162) and is required to engage in this quid pro quo if the domestic laws of the provider country prescribe ABS for genetic resources. Under the CBD, the term "genetic resources" covers all biological resources, with only "human genetic resources” explicitly excluded (CBD COP II/11, 1995). All viruses are considered genetic resources under the scope of the CBD and viruses are therefore subject to the same ABS terms as all other non-human genetic resources, unless covered by a "specialized instrument” in accordance with the Nagoya Protocol (Rourke, 2017, p. 85). These specialized instruments are likely to include the Food and Agriculture Organization of the United Nations’ International Treaty on Plant Genetic Resources for Food and Agriculture, adopted in 2004, 
and the World Health Organization's Pandemic Influenza Preparedness Framework for the Sharing of Influenza Viruses and Access to Vaccines and Other Benefits, adopted in 2011 (PIP Framework).

The ABS regimes established by the CBD and Nagoya Protocol govern not only the international sharing of genetic resources but also make provisions for the use of Traditional Knowledge (TK) associated with those resources and "held or owned” by Indigenous and local communities (ILCs). In effect, the CBD and Nagoya Protocol establish two overlapping schemes: one by the CBD, and the other by the CBD plus Nagoya Protocol. Article 8(j) of the CBD states that Contracting Parties are to "respect, preserve and maintain" TK and "encourage the equitable sharing of the benefits arising from the utilization of [TK]”. It also requires Contracting Parties to "[p]rotect and encourage customary use of biological resources in accordance with traditional cultural practices”. The Nagoya Protocol stipulates more concrete requirements, with Article 5(5) directing Parties to "take legislative, administrative or policy measures $[\ldots]$ in order that the benefits arising from the utilization of [TK] associated with genetic resources are shared in a fair and equitable way with [ILCs] holding such knowledge”.

Consequently, consideration must be given to the possible existence of TK associated with viral genetic resources that could factor in future virus ABS agreements under the CBD or CBD plus Nagoya Protocol. This superficially straightforward enquiry is made relatively complex by the competing interests of providers and users of genetic resources and associated TK, and the subsequent semantic discrepancies and differing interpretations of the CBD and Nagoya Protocol, particularly as ABS protocols and procedures differ across (and sometimes within) national jurisdictions. ${ }^{1}$ There is no agreed definition for the term "traditional knowledge" and both the CBD and Nagoya Protocol neglect to explicitly and conclusively define the concept. 
The issue of TK has been discussed in various United Nations fora, most notably the United Nations Environment Program (UNEP) which oversees the CBD and Nagoya Protocol and focuses on the ABS aspects of TK, and the World Intellectual Property Organization (WIPO) which is currently negotiating an instrument for the protection of TK under intellectual property (IP) frameworks (see Lawson, 2017). Even the most recent session of the Intergovernmental Committee on Intellectual Property and Genetic Resources, Traditional Knowledge and Folklore (IGC), convened by WIPO in 2001, acknowledged that there is no internationally accepted definition for TK (WIPO/GRTKF/IC/34/INF/7, 2017, p. 40). As the motivations and intent of UNEP and WIPO differ, so too do their working definitions of TK. ${ }^{2}$ This article will focus on the ABS aspects of viruses and associated TK, and will therefore approach TK through the lens of the CBD and Nagoya Protocol, both of which effectively defer the task of defining the scope of the term to individual nation States. However, it should be noted that some viruses and virus-derived products are functionally treated as patentable subject matter under the World Trade Organization's (WTO) Agreement on Trade-Related Aspects of Intellectual Property Rights (TRIPS Agreement) and that negotiations in other fora are likely to influence the definitional scope of TK. Certainly, the existence of virus-associated TK could impact the types of IP protections afforded to virus-related products, innovations and technological methods.

Further problems arise when trying to determine the required level of association with a genetic resource for TK to qualify as "traditional knowledge associated with genetic resources" as per the Nagoya Protocol (emphasis added). That is, what is the strength of the relationship that must exist between TK and the genetic resource in question to warrant consideration under ABS arrangements? This will be termed the "threshold of association" and in the context of the ABS regime created by the CBD and Nagoya Protocol together, this threshold may be low 
and capable of being defined by those ILCs that hold the apparently associated TK. In 2009, the CBD's group of legal and technical experts on TK suggested that "associated traditional knowledge refers to traditional knowledge which is specific or general in its relationship to genetic resources” (CBD/COP/WG-ABS/8/2, 2009; emphasis added). If this all-encompassing and inclusive threshold of association is used by individual Contracting Parties implementing domestic TK-specific ABS legislative, administrative or policy measures, then there will certainly exist TK associated with viral genetic resources that will qualify for the purposes of ABS. This article provides an overview of the types of TK that is indirectly associated with viruses, but more importantly, it demonstrates that even if a very high threshold of association is applied, there might still exist TK directly associated with viruses that could attract benefitsharing obligations.

This article begins with an overview of viruses as untapped reservoirs of genetic diversity and the growing recognition of their utility in commercial applications. The ABS regimes created by the CBD and Nagoya Protocol that apply to all genetic resources, including viruses, will be briefly outlined. The scientific value of TK and its historical exploitation will be discussed, as will instances of recognized TK associated with non-viral microbes. Finally, the article will provide examples of TK associated with viruses and will conclude that even if a high threshold of association is applied, there is likely to exist TK directly associated with viruses that will meet the requirements for consideration in ABS arrangements. This is significant because the use of virus-associated TK could be subject to benefit-sharing obligations in some jurisdictions and could potentially qualify for future IP protections. 


\section{Viruses: the ultimate genetic resource}

Viruses are sub-microscopic protein packages containing genetic material that can parasitize the cells of living organisms, hijacking their host's cellular machinery in order to replicate. Viruses are uniquely adept at evolving quickly, jumping species barriers and causing unpredictable and sometimes terrifying epidemics. As well as causing infectious diseases like influenza, polio, smallpox, Zika and Ebola, it is estimated that viruses are responsible for up to a fifth of all human cancers (McLaughlin-Drubin \& Munger, 2008, p. 127). Viruses are not just a problem for human health; viruses (and viroids) cause huge problems in farming and agriculture, and pose a significant threat to food security (Strange \& Scott, 2005, p. 83). Virus particles are comprised of either a DNA or RNA genome packaged within a protein capsid. They are ubiquitous and super-abundant, accounting for approximately 95 per cent of world's biological entities, while accounting for just five per cent of its overall biomass (Suttle, 2007, p. 803). It is thought that bacteriophages, the subset of viruses that infect bacteria "are reservoirs of the greatest uncharacterized genetic diversity on Earth” (Hambly \& Suttle, 2005, p. 444).

There is a lot of potential value to be garnered from these largely untapped and diverse genetic resources. Since Russian botanist Dimitri Ivanovski determined in the 1890s that a common disease of tobacco plants was not caused by bacteria, but by some filterable agent that turned out to be tobacco mosaic virus (Lechevalier, 1972), viruses have been used experimentally for myriad purposes. For instance, viruses have been a vital tool for understanding the functioning of the human immune system and they are required for the development of medicines and vaccines against the diseases they cause. Viruses are currently being used clinically as delivery vectors in gene and cancer treatments to transport therapeutic molecules into diseased cells (Russell, Peng \& Bell, 2012), and bacteriophages are being trialled as novel treatment options 
for common bacterial infections in an effort to counter the growing problem of antibiotic resistance (Golkar, Bagasra \& Pace, 2014).

The utility of viruses is now being recognized in biotechnological applications outside of the medical sphere. Novel technologies, particularly high-throughput genetic sequencing platforms and commensurate developments in computing power and bioinformatics, mean that scientists have expanded their horizons beyond just those viruses that are agriculturally relevant or that cause disease in humans (Roossinck, 2015). Viruses have been found to confer beneficial traits in various plant species, like drought and cold tolerance (Roossinck, 2015, p. 6533). They have also been recognized as useful agents in the treatment of human waste in activated sludge plants (Dyson, Tucci, Seviour, \& Petrovski, 2015; Pal, Khairnar, \& Paunikar, 2014; Thomas, Soddell, \& Kurtböke, 2002). A more complete picture of how viruses are involved in the global microbiome is emerging and indicates that viruses represent a latent source of unrealized value as industrial commodities. For small packets of genetic material, viruses represent a vast pool of untapped genetic diversity that can be put towards any number of practical applications. Finding ways to discover, identify, collect, characterize, reproduce, manipulate and utilize that diversity is critical for future developments and innovations, and will require ABS agreements that comply with the current legal requirements. Unlike many plants and animals that have been collected and stored in ex situ repositories which predate the CBD and Nagoya Protocol and to which these agreements probably do not apply (Kamau, Fedder \& Winter, 2010, p. 255), the vast diversity of viruses remain uncollected and will therefore be subject to the CBD and Nagoya Protocol ABS regimes.

While their recognition as CBD-regulated genetic resources was somewhat delayed, ${ }^{3}$ viruses are starting to attract the same sorts of regulations for ABS as has been common for over a 
decade for other types of genetic resources under the CBD (Rourke, 2017). Whether TK will be a factor in future virus ABS negotiations has not yet been considered. Given that viruses were not fully characterized by scientists until well into the $20^{\text {th }}$ Century, it is tempting to dismiss the possibility of ILCs developing specialized knowledge relating specifically to viruses. But humans have coevolved with viruses and viral diseases have undoubtedly shaped human health and influenced culture. Viruses of agricultural importance are also likely to have influenced our ancestors, spreading throughout and afflicting domesticated crops and livestock. As humans learned to live with and adapt to viruses, they very likely developed knowledge associated with these parasites. The growing understanding of the role of viruses in the biosphere (beyond their ability to cause human disease) and their application in biotechnology will result in the increasing commodification of viruses. It is crucial that we start to consider and debate the general terms on which these important genetic resources will be accessed and whether virus-associated TK has the potential to become a factor in future virus ABS negotiations.

\section{ABS under the CBD and Nagoya Protocol}

As genetic resources, viruses fall within the scope of the CBD. They are therefore subject to the same ABS regulations that are applicable to "genetic material of actual or potential value" of "plant, animal, microbial or other origin" as per Article 2 of the CBD. Article 1 outlines the objectives of the CBD to be "the conservation of biological diversity, the sustainable use of its components and the fair and equitable sharing of the benefits arising out of the utilization of genetic resources”. In an effort to link the access of biological resources to their conservation, Article 15 of the CBD explicitly reaffirms "the sovereign right of States over their genetic resources" and recognizes that "the authority to determine access to genetic resources rests with the national governments [of Contracting Parties] and is subject to national legislation”. 
Sovereign States therefore have the authority to determine what genetic resources attract ABS regulation, as well as the specific terms and conditions of ABS within their national jurisdiction. Article 15 further stipulates that access to genetic resources cannot be unreasonably restricted, must be on mutually agreed terms (MAT) and subject to prior informed consent (PIC).

The CBD was the first multilateral treaty to specifically recognize the importance of TK held by ILCs for the purposes of conservation. Accordingly, the Preamble to the CBD acknowledges "the desirability of sharing equitably benefits arising from the use of traditional knowledge, innovations and practices relevant to the conservation of biological diversity and the sustainable use of its components." Article 8(j) of the CBD then requires that Contracting Parties “respect, preserve and maintain” TK, “promote [the] wider application [of TK] with the approval and involvement of the holders of such [TK]" and encourages "the equitable sharing of benefits arising from the utilization of [TK]”. Article 17 requires Contracting Parties to "facilitate the exchange of information from all publicly available sources, relevant to the conservation and sustainable use of biological diversity" and this "shall include exchange of [...] indigenous and traditional knowledge". While creating some binding obligations regarding the protection of TK and its customary use, the CBD does not specifically create the conditions for a TK ABS scheme as it does for genetic resources, it merely encourages equitable benefit-sharing as a desirable outcome.

The Nagoya Protocol to the CBD was adopted by the Conference of the Parties (COP) to the CBD on 29 October 2010, and entered into force on 12 October 2014. The Nagoya Protocol is a supplemental agreement to the CBD, designed to clarify and "provide legal certainty" to the ABS and TK requirements of the original framework treaty (CBD/COP/10/27, 2010). Article 
3 of the Nagoya Protocol states that the Protocol applies "to genetic resources within the scope of Article 15 of the [CBD] and to the benefits arising from the utilization of such resources” as well as "traditional knowledge associated with genetic resources within the scope of the [CBD] and to the benefits arising from the utilization of such knowledge”.

Unlike the CBD, the Nagoya Protocol does create the conditions for a TK ABS scheme thereby bolstering "the ability of [ILCs] to benefit from the use of their knowledge, innovations and practices” as stated in the introduction to the Protocol. The Preamble to the Nagoya Protocol outlines the underlying assumptions on which its TK provisions rest: "the interrelationship between genetic resources and [TK]", the "inseparable nature” of TK and genetic resources, "the diversity of circumstances in which [TK] associated with genetic resources is held or owned by [ILCs]", "the right of [ILCs] to identify the rightful holders of their [TK] associated with genetic resources", and the different forms that TK might take as part of "a rich cultural heritage relevant for conservation and sustainable use of biological diversity”. That is, the Nagoya Protocol's use of the term "traditional knowledge” was to be all-encompassing, covering all types and aspects of TK. Furthermore, while the Nagoya Protocol draws its authority from Article $8(\mathrm{j})$ of the CBD, the Protocol draws its scope from the broader conception of TK addressed by the CBD as a whole.

In setting up the conditions for a bilateral ABS scheme for TK, Article 7 of the Nagoya Protocol requires that Parties "take legislative, administrative or policy measures, as appropriate, in order that the benefits arising from the utilization of [TK] associated with genetic resources are shared in a fair and equitable way with [ILCs] holding such knowledge”. The Preamble of the Nagoya Protocol states that ILCs have the right "to identify the rightful holders" of their TK and Article 5(5) states that access to TK associated with genetic resources, like access to the 
genetic resources themselves, is subject to the PIC (or approval and involvement) of the holders of TK, and the arrangement of MAT.

Unlike Article 8(j) of the CBD, the TK provisions of the Nagoya Protocol cannot be construed merely as aspirational, notwithstanding some instances of vague wording and soft obligations. Parties are expected to take legislative, administrative and policy measures to give domestic effect to their obligations under both the CBD and Nagoya Protocol. This means that these international instruments merely prescribe a sort of minimum standard for their Parties, affording a great deal of latitude for States to implement domestic ABS measures in line with their circumstances and priorities. Article 21(1) of the Nagoya Protocol encourages its Parties to include ILCs as stakeholders in the implementation of TK ABS measures, although the extent to which they do so is, again, up to the State. Unlike the CBD, the Nagoya Protocol comes with monitoring and compliance provisions, with Article 16 stipulating that Parties must take steps to ensure that the TK within their jurisdiction is accessed with PIC and MAT, "take appropriate, effective and proportionate measures to address situations of non-compliance” and “cooperate in cases of alleged violation”.

The consignment of ABS implementation to domestic jurisdictions has resulted in a patchwork of diverse ABS requirements for both genetic resources and the TK associated with them. How potential users of genetic resources and associated TK are required to conduct $\mathrm{ABS}$ negotiations depends upon the specific rules of the sovereign States from which the resources originate. Which specific forms of TK will be regulated under domestic rules is also up to individual States to decide. Inevitably, some States have stricter ABS requirements than others for both the genetic resources and any associated TK. When it comes to the ABS of TK specifically, the strength of those rules are very likely to reflect the strength of protections of 
Indigenous rights more broadly in any given State (Harry, 2011, p. 708). Therefore, for the purposes of determining whether TK may be associated with viral genetic resources, it is important to use the broadest possible conception of TK that could be adopted by any individual State.

\section{The scientific value of TK and its historical exploitation}

The regulation of TK is occurring in a context of growing international recognition of its value for both the ILCs that hold the TK, and the role that it can play in technological innovation. Historically dismissed as generalized and even quaint, TK is starting to be appreciated by some commentators as "scientific and holistic", "highly localised” and possessing "important social and legal dimensions” (Githae, 2009, p. 77). There is an increasing respect for TK as "a vital lead for inventions in pharmaceutical, cosmetic, agricultural and chemical industries” (Kamau, 2009, p. 143). So too is there a growing recognition of the rights of ILCs to control the terms of access to the TK that was previously "considered to be part of anthropological studies and [in] the public domain” (Roht-Arriaza, 1996, p. 926; see also Reichman, Uhlir and Dedeurwaerdere, 2016; pp. 84-87). Perhaps the most significant pressures are resulting from the political recognition of TK through WIPO, the United Nations Declaration on the Rights of Indigenous Peoples (UNDRIP) and the United Nations Educational, Scientific and Cultural Organization (UNESCO) (Lawson, 2017). It is very likely that the work in these fora will increase the focus on TK and associated genetic resources for the CBD and Nagoya Protocol.

Modern history is rife with stories of biopiracy and the exploitation of TK (see Robinson, 2012). In a process retrospectively referred to as "biocolonialism”, developing countries rich in biodiversity were historically exploited by developed countries and the most vulnerable populations in developing countries, ILCs, were disproportionately affected (Harry, 2011; 
Whitt, 1998). Almost all TK misappropriation stories that relate to genetic resources follow a similar template to that illustrated in the following example:

"A barley gene that confers resistance to the yellow-dwarf virus is the product of centuries of breeding and cultivation by Ethiopian farmers. U.S. farmers and the scientists who patented this barley variety receive substantial profits from its current cultivation in the U.S., but the Ethiopian farming communities that originally developed the variety receive nothing” (Roht-Arriaza, 1996, p. 924).

That is, the TK developed over many hundreds of years and passed from one generation to the next presents essential information for the development of a marketable product. The (usually Western) corporation patents and commercializes the "innovation" and accumulates benefits stemming from these resources and associated TK while the ILC (and the State in which they reside) is not recognized and/or does not share in any of the benefits. Furthermore, those protections and the overexploitation of their resources may even preclude the original TK holders from engaging in their traditional practices. There are two issues here: the first is the lack of engagement of ILCs at the point of access and/or utilization of their genetic resources and TK. This will be discussed further as it is the portion of the scenario directly addressed by the ABS provisions of the CBD and Nagoya Protocol. The second issue is the exclusion of ILCs during the patenting and commercialization process, occurring much later in the scenario than the point of access. The recognition and protection of TK under IP presents a separate but related set of problems that are currently being considered under the auspices of the WIPO (WIPO, 2017). For the purposes of this article, the recognition that virus-related TK could qualify for consideration under ABS regulations is sufficient to indicate that downstream uses of that same TK, including those uses that result in the granting of IP, may also be affected. It 
is difficult to determine precisely what this might entail until such time as clear guidelines are developed for the treatment of TK under international IP frameworks.

As viruses are genetic resources that are regulated just as any other genetic resource for ABS purposes, any TK associated with viruses will also attract regulation under the CBD and Nagoya Protocol. Scientists and product developers who use viruses in their research will need to be aware that if they are using viruses or associated TK then they will need to comply with the domestic laws and policies of the country from which those resources originate. In order to avoid allegations of biopiracy, researchers need to ensure that the benefits of scientific research into viruses are shared among those who developed the knowledge on which subsequent scientific developments rest. This will mean engaging ILCs as stakeholders ${ }^{4}$ in ABS negotiations at the point of accessing or utilizing genetic resources and associated TK. It should be noted here that there is still some ambiguity as to whether benefit-sharing obligations are triggered at the point of access or utilization. While the CBD uses "utilization” as the triggering event, the Nagoya Protocol "does not specify the moment at which the obligations to share benefits are triggered” (Daly, 2015, p. 372), but Article 2 of the Nagoya Protocol does define "[u]tilization of a genetic resource" as "to conduct research and development on the genetic and/or biochemical composition of genetic resources, including through the application of biotechnology as defined in Article 2 of the [CBD]”.

There are some assumptions here that have not been borne out in the literature: that there might exist TK associated with viruses at all and that if virus-associated TK does exist, that it would be scientifically useful for future innovations. Since virus-associated TK is something that has the potential to impact upon future virus ABS negotiations, it is important to scrutinize these assumptions. While it is impossible to disprove the existence of viral TK, this 'absence of 
evidence' argument is as unsatisfying as it is unsatisfactory in this case because regulation should not be directed at phantoms. In place of any documented instances of virus-associated TK, it is instructive to examine the features of TK associated with other, non-viral microbes.

The benefits of various species of bacteria have been long recognized by many ILCs. There are numerous instances of TK associated with bacterial genetic resources used in food, medicine and even textiles; the existence of TK associated with bacterial genetic resources is undisputed. For example, the Bharathidasan University in India hosts a Database on Microbial Traditional Knowledge containing information generated and held by Indian ILCs about fermented and pickled foods and beverages, as well as dyes derived from bacterial fermentation (Bharathidasan University, 2012). This is TK developed over centuries of experimentation by ILCs using various species of bacteria, despite never fully elucidating the precise biological nature of these microbes (as judged by the standards of modern Western science). This highlights three features of TK that are useful for this discussion. Firstly, TK can be considered scientific in the very real sense that it is derived by ILCs through the processes of observation, prediction and experimentation. Secondly, it is not necessary for ILCs to know the exact biological nature of the genetic resource, in this instance, the microorganism, to generate and use TK associated with that genetic resource. Very often the subject of TK is the bulk genetic resource as opposed to the isolated gene or compound responsible for the desired effect, i.e. the 'active ingredient'. Thirdly, TK is valuable and worthy of protection. India has deemed TK important enough to defend the TK of their ILCs by systematically cataloguing this knowledge, thus preventing other parties from acquiring adverse IP rights. ${ }^{5}$ These characteristics are likely to be the same for any virus-associated TK, but it should first be acknowledged that the term “associated” comes in degrees. 


\section{The threshold of association}

While the yellow-dwarf virus features in the above TK exploitation example, the TK itself is ostensibly associated with the barley variety as opposed to the virus to which it exhibits resistance. The genetic resource referred to in the example was the plant variety and the degree to which the plant variety is "associated" with the TK in this specific example is high. There are many, many examples of TK associated with plants. The Nagoya Protocol applies to “traditional knowledge associated with genetic resources”, but it does not specify the level of association that must exist for TK to qualify for ABS arrangements. As discussed, we must take the broadest possible conception of TK and its association in order to determine whether virus-related TK could exist that could attract ABS obligations. It may therefore be sufficient for TK to be indirectly associated with a virus (as is the case in the above example) for that TK to factor into virus ABS negotiations. There is no agreed strength or threshold of association that must be demonstrated before TK can be considered valid for ABS purposes. Indeed, individual States could adopt a range of TK association thresholds, from a relatively low threshold where ILCs themselves are the arbiters of what is and is not considered associated TK, right through to the highest threshold where TK must be proven to have a direct association with the genetic resource in question.

The above example indicates that there undoubtedly exists TK indirectly associated with viruses, as is the case for the yellow-dwarf virus-resistant barley variety. Indeed, it is not too difficult to find documented instances of indirect associations between TK and viruses. For example, in one study researchers screened the traditional dietary additives of Maasai healers from six villages in Kenya (Parker, Chabot, Ward \& Johns, 2007). The traditional healers were questioned as to which plant species they used to treat children with measles (caused by the highly contagious measles virus). Researchers screened 13 extracts of the most frequently 
named plant species and four of these were found to exhibit measles-neutralizing properties in cell culture (Parker et al., 2007). In this example, a direct association exists between the TK provided by the Maasai healers and the plants that were named, but there is also an indirect association between that same TK and the measles virus that those plants are used to treat. States where the domestic laws demand a relatively high threshold of association may not consider this indirect association sufficient to warrant consideration for ABS purposes. The following discussion will demonstrate, however, that even in States where a high threshold of association is required, there may indeed exist TK directly associated with viral genetic resources that could meet or exceed strict association requirements.

\section{TK directly associated with viruses}

That viruses are perceived as something humanity has always sought to eradicate, not actively conserve or utilize, may make them appear to be an unlikely candidate for the collection and dissemination of TK specifically and directly associated with them. As viruses are generally thought to have a negative value to humanity, any TK developed by ILCs is assumed to be about the treatment of the infection that the viruses cause and is therefore likely to be indirectly associated with the virus. There are, however, examples of TK directly associated with viruses where those viruses are found to confer some sort of advantage, and such instances would certainly qualify for ABS even with a high threshold of association.

The textbook example of a virus used for its beneficial properties is in the process of variolation. This was the collection of infectious material from patients with a mild smallpox infection used to deliberately infect other non-immune individuals to protect them from infection with more virulent strains of smallpox. These methods were developed independently in China, India and Africa centuries before the process was introduced and popularized in 
Europe in the $18^{\text {th }}$ Century (Riedel, 2005, p. 22). The effective but perilous process of variolation was improved by Edward Jenner who developed the first vaccine in 1796. Historical accounts of Jenner's innovation indicate that Jenner had overhead a milkmaid declaring “I shall never have smallpox for I have had cowpox. I shall never have an ugly pockmarked face” (Riedel, 2005, p. 23). Jenner began inoculating non-immune individuals with the cowpox virus, and demonstrated that this process was protective against human smallpox infection.

This makes for a useful thought experiment: might the milkmaid’s observation on the enduring immunity from smallpox for individuals who had contracted cowpox be considered akin to TK in today's regulatory climate? Would the knowledge of variolation that existed in China, possibly as early as the $16^{\text {th }}$ Century (Leung, 2011, p. 5) be considered TK? The answer to both these questions is, unequivocally, yes. Both would certainly meet a strict and high threshold of association requirement. ${ }^{6}$ Unlike other medical prophylaxis or treatment of viral infections, the agent in question is not a plant genetic resource as is so often the case with documented TK examples, but a viral genetic resource. For both variolation and vaccination, the TK that was appropriated and built upon and that ultimately led to the eradication of smallpox in 1980 was knowledge directly associated with viral genetic resources. Furthermore, not one of the traditional holders of this knowledge would have had the slightest clue as to the genetic nature of viruses themselves. The three abovementioned features of TK are present in both cases: the TK was derived through a scientific process of observation and experimentation, the nature of the genetic resource had not yet been elucidated, and the knowledge of variolation and vaccination was undeniably valuable to humankind. This thought experiment demonstrates that various cases of TK associated directly with a virus can meet and even exceed a high threshold of association and would therefore warrant consideration under some States’ ABS policies. 
A study of the history of virology reveals yet more scenarios where viruses were deemed by certain communities to possess realizable value. In $17^{\text {th }}$ Century Holland, tulips were a fashionable and covetable commodity. Within a few years of cultivation and selective breeding by the famous botanist, Carolus Clusius, a mottled variety of tulips arose that was particularly rare and sought-after (Lesnaw \& Ghabrial, 2000). The production of delicate broken patterns in the flowers was difficult to predict based on known breeding methods and botanists tried varying soil composition, temperature and pollination conditions to recreate this valuable tulip variety. The explosion in the trade of tulips in the Netherlands throughout the $17^{\text {th }}$ Century has been termed 'tulipmania' and the mottled tulip varieties would fetch unsustainably high prices, eventually leading to the collapse of the tulip speculation trade (Garber, 2016, pp. 337-340). The interesting point here for our purposes is that the botanists and speculators were unwittingly distributing not a special variety of tulips, but an aphid-borne potyvirus, the tulip breaking virus or tulip mosaic virus. The fashionable mottling of the petals was not a result of selective breeding, environmental variables or a particular cultivation technique, but a consequence of a virus infection that also reduced the lifespan of the tulip (actually increasing its rarity and pushing prices even higher) (Lesnaw \& Ghabrial, 2000). The idea that the mottling patterns were caused by an illness in the plant was never seriously entertained at the time (Goldgar, 2007, pp. 115-116), but breeders found that they were able to increase the incidence of mottling by grafting the bulbs of mottled (infected) plants onto plain (uninfected) varieties. The process of grafting, therefore, turned out to be the inadvertent but very purposeful propagation of a virus, so knowledge about grafting techniques and susceptibility patterns in tulip varieties constitutes knowledge associated with a virus. Tulipmania provides another historical example of the purposeful use of a virus the for its perceived (in this case aesthetic) value and provides yet another illustration of the sorts of TK directly associated with viruses 
that could today attract benefit-sharing obligations if used in the development of a marketable product.

\section{A virus-specific ABS framework without TK}

Article 4(4) of the Nagoya Protocol makes provision for specialized ABS instruments that apply to specific subsets of genetic resources. The only virus-specific international ABS scheme is the World Health Organization's Pandemic Influenza Preparedness Framework for the Sharing of Influenza Viruses and Access to Vaccines and Other Benefits (PIP Framework). Article 3 of the PIP Framework states that it applies only to those viruses that have the potential to cause a human influenza pandemic, and "does not apply to seasonal influenza viruses or other non-influenza pathogens or biological substances”. All other viruses therefore remain under the remit of the CBD and Nagoya Protocol. Article 4(4) of the Nagoya Protocol states that any specialized multilateral ABS agreements must be "consistent with, and [...] not run counter to the objectives of the [CBD] and [Nagoya] Protocol”. While TK was never a consideration during the drafting of the PIP Framework, because it forms a key component of the Nagoya Protocol (in which the Preamble recognizes the "inseparable nature" genetic resources and TK for ILCs), it could be argued that the PIP Framework should also take TK into account, should such a requirement arise. It is unclear as to whether States maintain sovereignty over "PIP biological materials" once they are provided through the PIP system and whether, therefore, the PIP Framework is in some way derogating from pre-existing obligations under the CBD and Nagoya Protocol. ${ }^{7}$ There is little doubt that States do relinquish some rights to viruses and other biological materials provided under the PIP Framework, but this does not preclude the possibility that States maintain sovereign interests over their PIP biological materials. If this is the case then the PIP Framework's ABS scheme could already be consistent with recognizing TK-related obligations under the CBD and Nagoya Protocol. If States do 
relinquish their sovereign rights to such materials, however, then the ABS arrangements under the PIP Framework might one-day need to incorporate specific provisions on TK if the Framework is to be recognized as a specialized instrument under Article 4(4) of the Nagoya Protocol.

It may be tempting to dismiss the possibility that an ILC would possess TK on potentially pandemic strains of the influenza virus, but this presents the same logical fallacy that was refuted earlier. Depending on the threshold of association that is applied, it is possible that knowledge about traditional poultry or pig farming practices that provide insights about a strain of influenza virus (its transmission, virulence, or the susceptibility of particular animals) might qualify. That TK associated with viruses seems initially implausible is probably more a consequence of a lack of imagination rather than an actual lack of TK.

\section{Conclusion}

This article has demonstrated that virus-associated TK could become a factor in future ABS negotiations. Even when a strict threshold of association is applied, there still might exist TK that is sufficiently associated with a virus to warrant consideration under the CBD and Nagoya Protocol's TK provisions. Centuries of deliberate use of pox viruses to induce immunity to smallpox and the intentional propagation of tulip breaking virus because of its effects on tulip aesthetics demonstrate that there have been instances of TK development with relation to viruses throughout recorded human history.

Precisely what form virus-associated TK ABS negotiations and arrangements might take is entirely another matter, one that has failed to generate a consensus view for TK more generally. Indeed, this has even proven difficult for the ABS of genetic resources themselves, an 
altogether more tangible and easily defined commodity than TK. This article does not attempt to deal with the many problems associated with putting TK ABS provisions in place, except to acknowledge that it is not remotely straightforward. There are difficulties in tracking the use of TK, sharing the benefits of utilization in a manner resembling "fair and equitable”, especially when the same TK is held by multiple ILCs. There are further problems associated with enforcing the patchwork of international ABS policies of varying standards as well as defining the precise triggering event for benefit-sharing and the delineation between commercial and non-commercial use of genetic resources and TK. There are a multitude of issues and there are no easy answers.

The CBD and especially the Nagoya Protocol do create some real requirements for the users of both genetic resources and any associated TK. The users of viral genetic resources and virusassociated TK will need to obtain the PIC of the ILCs that have established a right to provide access to those resources and their TK. They must also seek the approval and involvement of those ILCs and ensure that the utilization of their TK occurs on MAT. User Parties will need to abide by the domestic legislation of the country from which the TK originated and this is the case whether or not their own country is a Party to the CBD and/or the Nagoya Protocol. In situations where PIC and MAT are not met, ILCs may be able to seek recourse for the exploitation of their TK through domestic channels that are backed by the compliance provisions in Article 16 of the Nagoya Protocol. The key point here is that there is a mounting intolerance to brazen instances of biopiracy and the misappropriation of the TK of ILCs. Any users of TK who fail to meet their ABS requirements, or neglect, at the very least, to engage with ILCs, risk reputational damage and attracting the ire of the international community. Large scale users of genetic resources such as pharmaceutical manufacturers and the biotech industry 
are likely to be judged particularly harshly if they are seen to be taking advantage of vulnerable populations.

As scientists begin to recognize the beneficial ways in which viruses and their unique genetic properties can be harnessed (Roossinck, 2015, p. 6533), their value as biotechnology commodities will rise. Countries are free to implement domestic ABS legislation and policy as they see fit (within the bounds of the CBD and/or the Nagoya Protocol, as appropriate) and there is no standardized agreement for the ABS of most viruses, so every transaction is negotiated on a case-by-case basis (other than for pandemic influenza viruses, as discussed). Therefore, all ABS stakeholders: providers and users of genetic resources, and especially ILCs, should be aware that virus-associated TK can now be brought to the bargaining table. 


\section{REFERENCES}

Bharathidasan University. (2012). Database on Microbial Traditional Knowledge of India. Retrieved November 23, 2016, from http://www.bdu.ac.in/schools/biotechnology/industrial_biotechnology/sekardb.htm

Daly, A. (2015). Legislating on biopiracy in Europe: too little, too late? In M. Rimmer (Ed.), Indigenous Intellectual Property: A Handbook of Contemporary Research (pp. 365381). Edward Elgar. http://doi.org/http://dx.doi.org/10.4337/9781781955901.00026

Dyson, Z. A., Tucci, J., Seviour, R. J., \& Petrovski, S. (2015). Lysis to kill: Evaluation of the lytic abilities, and genomics of Nine bacteriophages infective for Gordonia spp. and their potential use in activated sludge foam biocontrol. PLOS ONE, 10(8), 1-16. http://doi.org/10.1371/journal.pone.0134512

Garber, P. (2016). Tulipmania. In G. Jones (Ed.), Banking Crises. Palgrave Macmillan. Githae, J. K. (2009). Potential of Traditional Knowledge for Conventional Therapy Prospects and Limits. In E. C. Kamau \& G. Winter (Eds.), Genetic Resources, Traditional Knowledge and the Law: Solutions for Access and Benefit Sharing. Earthscan.

Goldgar, A. (2007). Tulipmania: Money, Honor, and Knowledge in the Dutch Golden Age. University of Chicago Press.

Golkar, Z., Bagasra, O., \& Pace, D. G. (2014). Bacteriophage therapy: A potential solution for the antibiotic resistance crisis. Journal of Infection in Developing Countries, 8(2), 129-136. http://doi.org/10.3855/jidc.3573

Hambly, E., \& Suttle, C. A. (2005). The viriosphere, diversity, and genetic exchange within phage communities. Current Opinion in Microbiology, 8(4), 444-450. http://doi.org/10.1016/j.mib.2005.06.005 
Harry, D. (2011). Biocolonialism and Indigenous Knowledge in United Nations Discourse. Griffith Law Review, 20(3), 702-728. http://doi.org/10.1080/10383441.2011.10854717

Kamau, E. C. (2009). Protecting Traditional Knowledge Amid Disseminated Knowledge - A New Task for Access and Benefit Sharing Regimes? A Kenyan Legal View. In E. C. Kamau \& G. Winter (Eds.), Genetic Resources, Traditional Knowledge and the Law: Solutions for Access and Benefit Sharing. Earthscan.

Kamau, E. C., Fedder, B., \& Winter, G. (2010) The Nagoya Protocol on Access to Genetic Resources and Benefit Sharing: What is New and What are the Implications for Provider and User Countries and the Scientific Community? Law, Environment and Development Journal, 6(3), 246-262.

Lawson, C. (2006). Regulating Access to Biological Resources: The Market Failure for Biodiversity Conservation. Law in Context, 24(1), 137-163.

Lawson, C. (2017). Relationships between the work of the WIPO IGC and other forums. In D. Robinson, A. Abdel-Latif, \& P. Roffe (Eds.), Protecting Traditional Knowledge: The WIPO Intergovernmental Committee on Intellectual Property and Genetic Resources, Traditional Knowledge and Folklore. Routledge.

Lechevalier, H. (1972). Dmitri Iosifovich Ivanovski (1864-1920). Bacteriological Reviews, 36(2), 135-45.

Lesnaw, J. A., \& Ghabrial, S. A. (2000). Tulip Breaking: Past, Present, and Future. Plant Disease, 84(10), 1052-1060.

Leung, A. K. C. (2011). "Variolation” and Vaccination in Late Imperial China, Ca 15701911. In S. A. Plotkin (Ed.), History of Vaccine Development. Springer.

McLaughlin-Drubin, M. E., \& Munger, K. (2008). Viruses associated with human cancer. Biochimica et Biophysica Acta, 1782(3), 127-150. http://doi.org/10.1016/j.bbadis.2007.12.005 
Oberthür, S., \& Rosendal, G. K. (2014). Global Governance of Genetic Resources :

Background and Analytical Framework. In S. Oberthür \& G. K. Rosendal (Eds.), Global

Governance of Genetic Resources: Access and Benefit Sharing after the Nagoya

Protocol. New York: Routledge, Taylor and Francis.

Pal, P., Khairnar, K., \& Paunikar, W. N. (2014). Causes and remedies for filamentous foaming in activated sludge treatment plant. Global Nest Journal, 16(4), 762-772.

Parker, M. E., Chabot, S., Ward, B. J., \& Johns, T. (2007). Traditional dietary additives of the Maasai are antiviral against the measles virus. Journal of Ethnopharmacology, 114(2), 146-152. http://doi.org/10.1016/j.jep.2007.06.011

Reichman, J. H., Uhlir, P. F., \& Dedeurwaerdere, T. (2016) Governing Digitally Integrated Genetic Resources, Data, and Literature: Global Intellectual Property Strategies for Redesigned Mircobial Research Commons. New York: Cambridge University Press. Riedel, S. (2005). Edward Jenner and the history of smallpox and vaccination. Baylor University Medical Center Proceedings, 18, 21-25. http://doi.org/10.1159/000322101

Robinson, D. F. (2012). Confronting Biopiracy: Challenges, Cases and International Debates. New York: Earthscan.

Roht-Arriaza, N. (1996). Of Seeds and Shamans: The Appropriation of the Scientific and Technical Knowledge of Indigenous and Local Communities. Michigan Journal of International Law, 17, 919-965.

Roossinck, M. J. (2015). Move Over, Bacteria! Viruses Make Their Mark as Mutualistic Microbial Symbionts. Journal of Virology, 89(13), 6532-6535.

http://doi.org/10.1128/JVI.02974-14

Rourke, M. F. (2017). Viruses for sale: all viruses are subject to access and benefit-sharing obligations under the Conventional on Biological Diversity. European Intellectual Property Review, 39(2), 79-89. 
Russell, S. J., Peng, K.-W., \& Bell, J. C. (2012). Oncolytic virotherapy. Nature Biotechnology, 30(7), 1-13. http://doi.org/10.1016/j.jvir.2013.05.040

Sedyaningsih, E. R., Isfandari, S., Soendoro, T., \& Supari, S. F. (2008). Towards mutual trust, transparency and equity in virus sharing mechanism: The avian influenza case of Indonesia. Annals of the Academy of Medicine Singapore, 37(29), 482-488.

Strange, R. N., \& Scott, P. R. (2005). Plant Disease: A Threat to Global Food Security. Annual Review of Phytopathology, 43(1), 83-116. http://doi.org/10.1146/annurev.phyto.43.113004.133839

Suttle, C. A. (2007). Marine viruses - major players in the global ecosystem. Nature Reviews Microbiology, 5(10), 801-812. http://doi.org/10.1038/nrmicro1750

Thomas, J. A., Soddell, J. A., \& Kurtböke, D. Í. (2002). Fighting foam with phages? Water Science and Technology, 46(1), 511-518.

Whitt, L. A. (1998). Biocolonialism and the commodification of knowledge. Science as Culture, 7(1), 33-67. http://doi.org/10.1080/09505439809526490 WIPO. (2017). Intergovernmental Committee (IGC). Retrieved April 7, 2017, from http://www.wipo.int/tk/en/igc/ 
${ }^{1}$ For instance, in Australia ABS is governed at the national level by the Environment Protection and Biodiversity Conservation Act 1999, but its jurisdiction is limited in that it only applies in Commonwealth areas. Other areas are covered by State and Territory Government legislation and other areas still are the domain of private landholders and lie outside of the scope of the CBD. ${ }^{2}$ While both UNEP and WIPO have had to deal with similar problems, the focus of each body is different and they must therefore contend with a series of specific problems. With regard to the management of TK using IP protections, problems include whether existing IP models of protection are suitable for TK, whether protective or defensive approaches should be taken and what duration protections should be applied.

${ }^{3}$ The CBD entered into force on 29 December 1993 but the first recognized application of the CBD specifically to viruses was in 2007 when then Indonesian Health Minister, Dr Siti Fadilah Supari claimed sovereignty over Indonesia’s H5N1 pandemic influenza virus samples (see Sedyaningsih, Isfandari, Soendoro, \& Supari, 2008).

${ }^{4}$ The CBD has been criticized for relegating Indigenous peoples to the status of stakeholders, even in the use of the term ILC instead of “Indigenous peoples” as “it ignores Indigenous peoples' status as rights-holders in international law" (Harry, 2011, p. 709). The term is used here in keeping with the original language of the CBD. It should also be noted that there is some ambiguity regarding precisely who can identify as "indigenous and local communities" in accordance with the CBD and Nagoya Protocol. The United Nations Permanent Forum on Indigenous Issues recommended that the terminology “indigenous and local communities” be updated to “'indigenous peoples and local communities' as an accurate reflection of the distinct identities developed by those entities since the adoption of the [CBD] almost 20 years ago" (E/2011/43-E/C.19/2011/14, 2011, p. 6). While the CBD's COP agreed to this change in terminology at the CBD and Nagoya Protocol forums, and that it would not have any legal effect (CBD COP XII/12(F), 2013 and CBD/COP/12/5, 2013, p. 6), the consequence has been to separate out “indigenous peoples” and “local communities”. 
${ }^{5}$ According to the WIPO (WIPO/GRTKF/IC/5/12, 2003, p. 11), “[a] positive protection strategy is based on obtaining and asserting rights in the protected material, while a defensive protection strategy is aimed at preventing others from gaining or maintaining adverse IP rights”.

${ }^{6}$ Indeed, the milkmaids may even be said to constitute a "local community" in accordance with the usage of the term in the Nagoya Protocol.

7 “PIP biological materials" are defined by the PIP Framework to include "human clinical specimens, virus isolates of wild type human H5N1 and other influenza viruses with human pandemic potential; and modified viruses prepared from H5N1 and/or other influenza viruses with human pandemic potential” including “candidate vaccine viruses generated by reverse genetics and /or high growth reassortment”, as well as "RNA extracted from wild-type H5N1 and other human influenza viruses with human pandemic potential and cDNA that encompass the entire coding region of one or more viral genes”. What is referred to here as the "PIP system” is called the WHO's Global Influenza Surveillance and Response System (GISRS) and encompasses a network of WHO-approved participating laboratories from around the world, formerly called the Global Influenza Surveillance Network (GISN) prior to the implementation of the PIP Framework in 2011. It should be noted that it is presently unclear as to whether the PIP Framework formally qualifies as a "specialized instrument" under Article 4(4) of the Nagoya Protocol. The PIP Advisory Group is still seeking clarification on this matter (WHO EB140/16, 2016, p. 96). 